\title{
Assessment of Etiology of Elephantiasis and Its Associated Risk Factors in Jeldu District, West Shoa, Ethiopia
}

\author{
Ararsa Negasa ${ }^{1}$ and Mebrate Dufera $\mathbb{D}^{2}$ \\ ${ }^{1}$ Jeldu Preparatory School, West Shoa Zone, Gojo, Jeldu, Ethiopia \\ ${ }^{2}$ Department of Biology, College of Natural and Computational Sciences, Wollega University, Nekemte, Ethiopia
}

Correspondence should be addressed to Mebrate Dufera; mebrateduferah@gmail.com

Received 19 January 2021; Revised 30 March 2021; Accepted 7 April 2021; Published 15 April 2021

Academic Editor: Pedro P. Chieffi

Copyright (c) 2021 Ararsa Negasa and Mebrate Dufera. This is an open access article distributed under the Creative Commons Attribution License, which permits unrestricted use, distribution, and reproduction in any medium, provided the original work is properly cited.

\begin{abstract}
Elephantiasis is the main cause of tropical lymphoedema in Ethiopia. The aim of the current study was to assess the etiology of elephantiasis and its associated risk factors. Cross-sectional community-based study was carried out from March to May 2020 in seven purposively selected villages of Jeldu district. Identified suspected cases of elephantiasis in those villages were interviewed, clinically observed, and serologically examined using filariasis test strip kits at their respective houses during day time. A midnight blood sample was obtained from all FTS positive cases for microscopic examination of Wuchereria bancrofti larva, microfilariae. From a total of 105 identified elephantiasis cases, 69.5\% were podoconiosis cases and 30.5\% were LF cases. Among 32 serologically positive cases, only $15.6 \%$ cases were found positive by parasitological blood diagnosis. Considerable cases of podoconiosis (37\%) were at age range $26-40$ years, whereas smallest cases (16.4\%) were at 10-25 years. Among cases of podoconiosis and LF, 77 subjects have been developed overt chronic leg(s) swelling; $85.7 \%$ of them showed bilateral swelling below knee and $14.3 \%$ of them showed unilateral swelling with stage II swelling $41.1 \%$. Regarding risk factors, odds of podoconiosis was greatly lower in participants who washed their legs daily when compared to those who washed their legs sometimes $(P=0.002)$. Odds of LF was higher in people who used bed nets/IRS and they were more protected than those who did not use bed nets/IRS $(P=0.03)$. Odds of LF was high in cases farming besides rivers and/or perform irrigation work $(P=0.003)$. The highest silicon concentration $4.65 \mathrm{mg} /$ $10 \mathrm{gm}$ in Urgaha is coinciding with the highest podoconiosis cases $(23.3 \%)$ of the village. Family history was a significant risk factor for the disease $(P \leq 0.001)$. Age $(26-40$ years), sex, and leg hygiene were also strong risk factors. Both etiologies of elephantiasis, LF and podoconiosis, are geographically overlapped in Jeldu district.
\end{abstract}

\section{Introduction}

Lymphatic filariasis (LF) is a neglected tropical disease that persists in developing countries and impoverished communities throughout Sub-Saharan Africa, Asia, South, and Central America and Pacific Island nations. Globally, it has been estimated that more than 1.3 billion people, most of whom are the world's poorest, are at risk for contracting LF, with 120 million infected and about 40 million disfigured or incapacitated people by the disease [1]; more than onethird of these are in Sub-Saharan Africa. Among SubSaharan Africans, Congo, Nigeria, Tanzania, Rwanda, Kenya, and Ethiopia are at risk of LF [2]. Elephantiasis represents a major public health problem in tropical and subtropical regions of the world, which is characterized by the thickening of the skin and underlying subcutaneous tissues, especially in the legs and male genitals and female breasts, causing permanent disability $[3,4]$. Historically, in Ethiopia, the first case of LF was reported in 1971 [5]. Entomological investigations (human landing catch followed by dissection of mosquito) in Gambella show that Anopheles gambiae s.l. (probably A. arabiensis) and A. funestus were the main vectors of Wuchereria bancrofti, with no evidence for the involvement of the culicine mosquitoes despite the high biting rates [5]. Additionally, [6] identified the five LF endemic districts in Ethiopia namely, South-Ari, Benatsemay and Selemago, Teltele, Simada, and Tach-Gayint. 
Non-filarial elephantiasis (podoconiosis) is a chronic inflammatory, geochemical skin disease caused by prolonged exposure to irritant red clay soils derived from volcanic rocks and causes bilateral asymmetrical swelling of the lower legs. It is the second most common cause of tropical lymphoedema after lymphatic filariasis and is characterized by prominent swelling of the lower extremities, which leads to disfigurement and disability [7]. Globally, the disease occurs in highland areas of tropical Africa, Central America, and northwest India and is related to poverty. It is estimated to affect 4 million people worldwide [8]. Podoconiosis which is common in areas of particular soil composition has been reported from Ethiopia, Uganda, Kenya, Tanzania, Rwanda, Burundi, and the Sudan where its distribution overlaps that of bancroftian filariasis $[8,9]$. Furthermore, podoconiosis was reported from Gojjam, Northern Ethiopia by [10] during the markets survey in 1969; there were more than 100,000 cases in Ethiopia at the time.

Generally, recent assessments suggest that Ethiopia is projected to bear one-fourth (25\%) of the global burden of podoconiosis, with up to 1 million cases of podoconiosis existing in Ethiopia [11]. LF also exposes an estimated 5.7 million people at risk of infection [12]. Therefore, these two neglected tropical diseases apparently lead to elephantiasis and therefore have fundamental public health importance [3]. Based on this information, this study is primarily designed for further investigation of cases, etiologies, and associated risk factors of elephantiasis in Jeldu district, West Shoa, Ethiopia.

\section{Methods}

2.1. Study Area. A cross-sectional community-based cases survey was conducted from March to May 2020 in seven purposively selected villages: Fallo, Goro, Haro, Osole, Suki, Taso and Urgaha of Jeldu district, West Shoa, Ethiopia. The district is located $114 \mathrm{~km}$ far from Addis Ababa and situated between $9^{\circ} 22^{\prime} 30^{\prime \prime}$ to $9^{\circ} 31^{\prime} 30^{\prime \prime} \mathrm{N}$ latitudes and $37^{\circ} 57^{\prime} 0^{\prime \prime}$ to $38^{\circ} 6^{\prime} 0^{\prime \prime} \mathrm{E}$ longitudes direction (Figure 1).

\subsection{Clinical, Serological, and Parasitological Examinations.} Primary data collection was conducted in three phases. In the first phase, a pilot study was conducted on the study area one week prior to actual data collection to identify the presence of elephantiasis. In the second phase, uniquely triangulated actual data collections were maintained: elephantiasis clinical picture observation, responses from semi-structured questionnaire, and serological blood examination by FTS by collecting $75 \mu \mathrm{L}$ blood from ring finger of each participants. Suspected cases were also clinically observed for signs of the limb lymphoedema and then lymphoedema severity was graded and outlined by [13].

On the third phase, those cases who were found positive by FTS were re-sampled and the blood was taken from each participant from their ring finger at night between 8 p.m. and 4 a.m. at their respective houses.

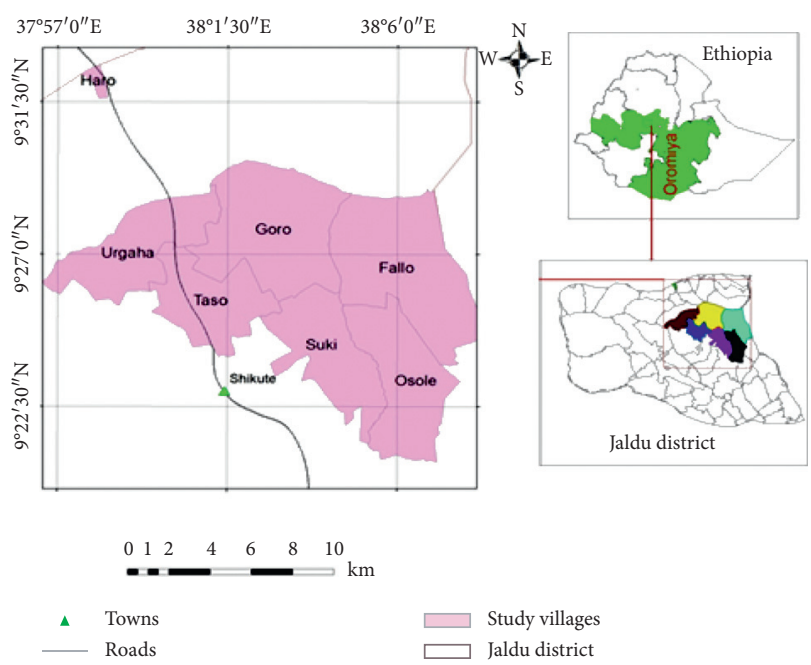

Figure 1: The study area map, Jeldu district, West Shoa, Ethiopia.

Nocturnal blood collection was carried out because of nocturnal periodicity of the parasite $[14,15]$. About $40 \mu \mathrm{L}$ finger prick blood was collected and stained to detect microfilariae. Microfilariae (no microfilariae/40 $\mu \mathrm{L}$ ) were also counted by two laboratory professionals. Types and physical and chemical properties of the soil are fundamental risk factors for occurrence of podoconiosis [16]. Therefore, randomly collected $300 \mathrm{gm}$ of soil samples from each village was coded and transported to Holeta Agricultural Research Center (HARC) West Shoa, Ethiopia, for the mineral analysis.

\section{Results}

3.1. Sociodemographic Characteristics. Among a total of 392 study participants, 203 (51.8\%) males and 189 (48.2\%) females were interviewed as suspected cases of elephantiasis in the seven villages of the district, and 13 suspected individuals refused to give their blood sample. Therefore, clinical examination and serological blood diagnosis using FTS were done for 379 individuals, 194 (51.2\%) males and 185 (48.8\%) females, during second phase of the study. Of those participants, $55(14.5 \%)$ suspected available cases were selected from Fallo Village while 36 (9.5\%), 62 (16.4\%), 60 (15.8\%), 57 (15\%), 60 (15.8\%), and 49 (12.9\%) were selected from Goro, Haro, Osole, Suki, Taso, and Urgaha, respectively. From a total of 105 identified elephantiasis cases, 73 (69.5\%), 48 (45.7\%) males and 25 (23.8\%) females, were podoconiosis cases and 32 (30.5\%), 12 (11.4\%) males and 20 (19.1\%) females, were LF cases. However, co-infection was not detected.

Considerable cases of podoconiosis $(37 \%)$ were at age range 26-40 years, whereas smallest cases (16.4\%) were at 10-25 years. Males (65.7\%) were more affected than females (Table 1).

3.2. Physical (Clinical) Observation. The physical observation was made for all 379 individuals by two clinical nurses in response to identify the etiologies of elephantiasis on the 
TABle 1: Sex and age distribution of podoconiosis cases $(n=73)$ in Jeldu district, West Shoa, Ethiopia.

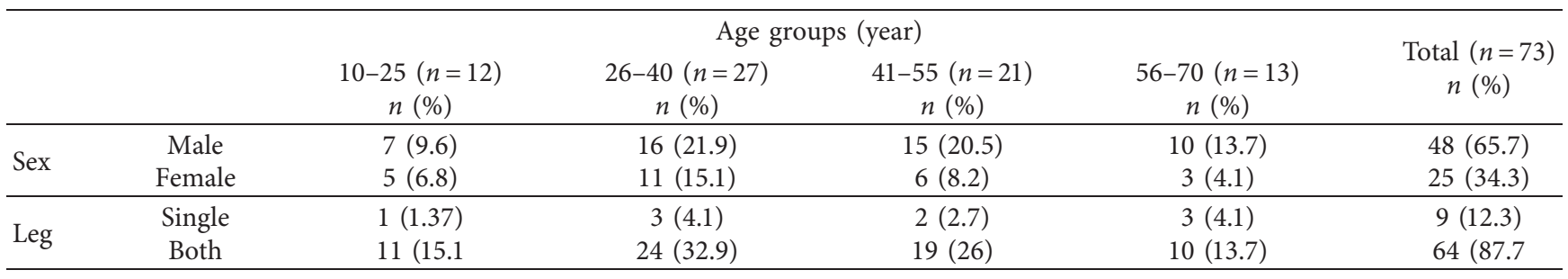

TABle 2: Type and sites swelling of elephantiasis cases $(n=77)$ in Jeldu district, West Shoa, Ethiopia.

\begin{tabular}{lccc}
\hline & & Elephantiasis & \\
& Podo $(n=73) n(\%)$ & TF $(n=4) n(\%)$ & $49(63.6)$ \\
Sex & $48(62.3)$ & $1(1.3)$ & $28(36.4)$ \\
Male & $25(32.5)$ & $3(3.9)$ & $66(85.7)$ \\
Female & $64(83.1)$ & $2(2.6)$ & $10(13)$ \\
\hline Site of swelling & $8(10.4)$ & $2(2.6)$ & $1(1.3)$ \\
Bilateral below knee & $1(1.3)$ & $0(0)$ & \\
Unilateral below knee & $67(87)$ & $4(5.2)$ & $71(92.2)$ \\
Unilateral above knee & $6(7.8)$ & $0(0)$ & $6(7.8)$ \\
\hline Type of swelling & & & $\leq 0.001$ \\
Fibrotic (hard) & & & \\
Watery (soft) & & & \\
\hline
\end{tabular}

TAвLE 3: Stages of podoconiosis cases $(n=73)$ in Jeldu district, West Shoa, Ethiopia.

\begin{tabular}{lcccccc}
\hline \multirow{2}{*}{ Podo cases } & \multicolumn{9}{c}{ Stages } & & \multirow{2}{*}{ Total $(n=73) n(\%)$} & $P$ value \\
& & I $(n=25) n(\%)$ & II $(n=30) n(\%)$ & III $(n=16) n(\%)$ & IV $(n=2) n(\%)$ & 0.04 \\
\multirow{2}{*}{ Sex } & Male & $15(20.5)$ & $19(26.1)$ & $12(16.4)$ & $2(2.7)$ & $48(65.7)$ \\
& Female & $10(13.7)$ & $11(15.0)$ & $4(5.5)$ & $0(0)$ & $25(34.3)$ \\
\hline \multirow{4}{*}{ Age } & $10-25$ & $6(8.2)$ & $4(5.5)$ & $2(2.7)$ & $0(0)$ & $12(16.4)$ \\
& $26-40$ & $5(6.8)$ & $14(32.6)$ & $8(11)$ & $0(0)$ & $27(37)$ \\
& $41-55$ & $12(16.4)$ & $7(9.6)$ & $2(2.7)$ & $0(0)$ & $21(28.8)$ \\
& $56-70$ & $2(2.7)$ & $5(6.8)$ & $4(5.5)$ & $2(2.7)$ & $13(17.8)$ \\
\hline
\end{tabular}

basis of their clinical algorithm and grading the severity of swelling. Among those participants, 77 (19.5\%) people were developed observable legs swelling and identified as elephantiasis cases by ruling out other encountered lymphoedema like leprosy, tungiasis, and other skin disorders. Of the 77 people, leg swelling of $64(83.1 \%)$ podoconiosis cases and 2 (2.6\%) LF cases were bilateral symmetry below knee. However, breast swelling and scrotal swelling (hydrocele) which are the best feature of LF were not observed. Furthermore, of 32 LF cases only 4 (5.2\%) individuals developed observable leg swelling. Sites and type of swelling have strong statistical association with elephantiasis $(P \leq 0.001)$ (Table 2).

Of the two etiologies of elephantiasis identified from the study area, participants affected by podoconiosis developed overt chronic swelling while most LF positive cases seemed asymptomatic; only four individuals developed stage I swelling. Of four stages of lymphoedema identified among podoconiosis confirmed cases, stage IV was very rare $(2.7 \%)$ but stage II was common 30 (41.1\%). When severity stages of podoconiosis were considered relative to age groups, stages of podoconiosis showed significant association with age groups $(P=0.02)$. The majority of the cases also suggested that they got reduction (decrease) in the size of their swelling after wearing covered shoes (Table 3 ).

Regarding the distribution of LF and podoconiosis within the villages, most (17.14\%) cases of podoconiosis were reported from Urgaha Village, while most (15.24\%) cases of LF were from Haro Village, and least (4.76\%) cases of podoconiosis were recorded in Haro Village. LF case was not recorded in Taso (Figure 2).

3.3. Serological and Parasitological Blood Examination. In the third phase of the study, cases that became positive by FTS were re-sampled for parasitological blood diagnosis, double-checked. Parasitological (thick blood smear) examination was performed for all FTS positive individuals during nighttime. Fortunately, of those 32 positive cases only 5 (15.6\%) individuals, 3 (9.4\%) females and 2 (6.2\%) males, were identified positive for larva of Wuchereria bancrofti microfilariae (Table 4).

3.4. FTS Kits Intensity and Microfilariae Density. Although significance differences were not observed in both sex and age groups, higher mean of $\mathrm{mf} / 40 \mu \mathrm{L}$ (5) was 


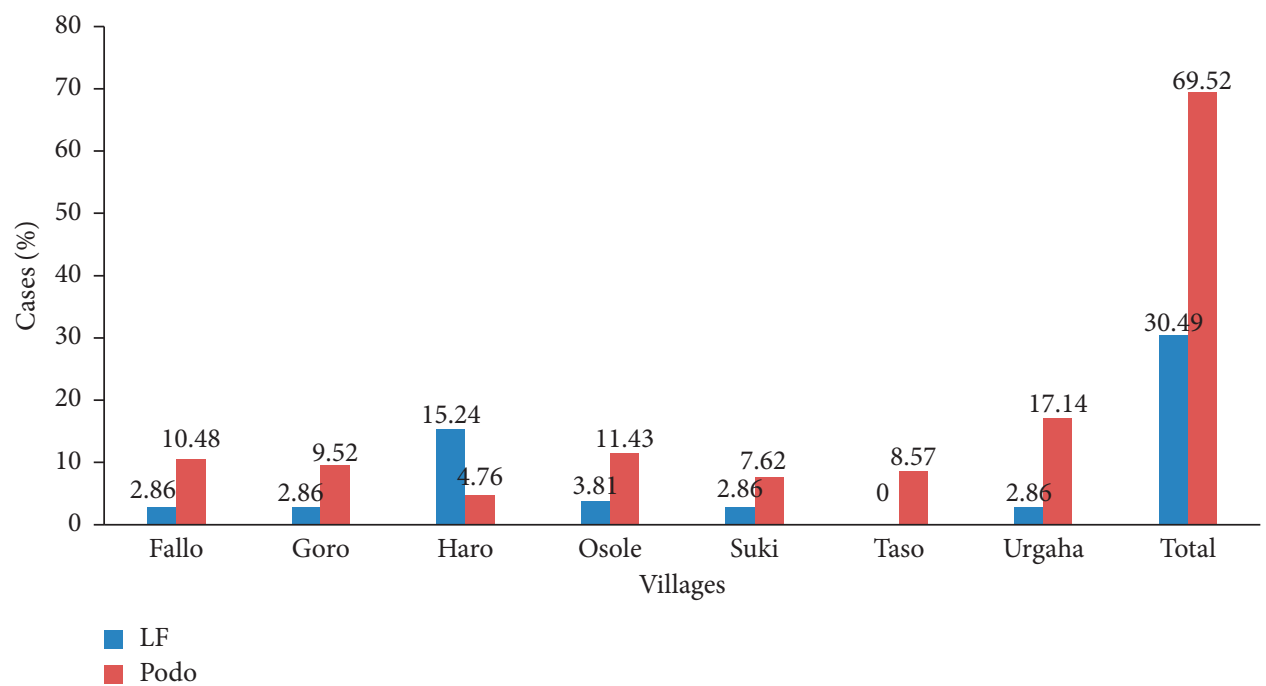

FIgure 2: Distribution of LF and podoconiosis within the study villages $(n=105)$, Jeldu district, West Shoa, Ethiopia.

TABle 4: LF cases and the diagnostic tools in Jeldu district, West Shoa, Ethiopia.

\begin{tabular}{ccccc}
\hline & LF cases & \multicolumn{2}{c}{ Diagnostic tools } & Both $(n=5) n(\%)$ \\
& & FTS + ve $(n=32) n(\%)$ & Microscope + ve $(n=5) n(\%)$ & $2(6.2)$ \\
Sex & Male & $12(37.5)$ & $3(6.2)$ & $3(9.4)$ \\
\hline
\end{tabular}

TABLE 5: Intensity of FTS kits of LF cases $(n=32)$ with relative age and sex in Jeldu district, West Shoa, Ethiopia.

\begin{tabular}{ccccccc}
\hline & & & & \\
& & & Intensity of kits \\
& Low $(n=19) n(\%)$ & Medium $(n=7) n(\%)$ & High $(n=6) n(\%)$ & Total $(n=32) n(\%)$ & Mean mf/40 $\mu \mathrm{L}$ & $P$ value \\
\hline \multirow{2}{*}{ Sex } & Male & $8(25)$ & $3(9.4)$ & $1(3.1)$ & $12(37.5)$ & 3 \\
& Female & $11(15.1)$ & $4(12.5)$ & $5(15.6)$ & $20(62.5)$ & 0.27 \\
\hline
\end{tabular}

TABLE 6: Soil mineral types of the study villages in Jeldu district, West Shoa, Ethiopia.

\begin{tabular}{lccccccc}
\hline \multirow{2}{*}{ Study villages } & \multicolumn{3}{c}{ Type of minerals $(\mathrm{mg} / 10 \mathrm{gm})$} & & \multirow{2}{*}{ PH } & Podoconiosis cases $n(\%)$ \\
& Aluminium $(\mathrm{Al})$ & Iron $(\mathrm{Fe})$ & Silicon $(\mathrm{Si})$ & Potassium $(\mathrm{K})$ & Calcium $(\mathrm{Ca})$ & & \\
\hline Fallo & 0.98 & 4.05 & 2.87 & 5.38 & 4.55 & 7.3 & $12(16.4)$ \\
Goro & 0.83 & 3.96 & 3.51 & 9.44 & 7.21 & 7.1 & $7(9.5)$ \\
Haro & 0.55 & 2.93 & 0.72 & 8.23 & 10.41 & 6.7 & $5(6.8)$ \\
Osole & 1.67 & 8.71 & 3.42 & 7.12 & 5.12 & 7.4 & $14(19.2)$ \\
Suki & 1.07 & 3.28 & 1.22 & 12 & 3.8 & 6.9 & $8(11)$ \\
Taso & 0.82 & 3.82 & 1.36 & 6.43 & 2.33 & 7.1 & $10(13.7)$ \\
Urgaha & 2.21 & 4.64 & 4.65 & 1.39 & 10.5 & 7.5 & $17(23.3)$ \\
\hline
\end{tabular}

observed in females and with regard to age, mean of $\mathrm{mf} /$ $40 \mu \mathrm{L}$ (4) was observed in age ranges $41-55$. Intensity of the kits was also graded based on redness of the test lines; majority of cases $19(61.3 \%)$ recorded low intensity (Table 5).

In addition to clinical, immunological, and parasitological findings, soil mineral analysis was carried out to diagnose podoconiosis; therefore, concentration of aluminium, iron, potassium silicon, and calcium was determined in seven soil samples taken from each selected village. The highest silicon concentration $(4.65 \mathrm{mg} / 10 \mathrm{gm})$ in alkaline soil $(\mathrm{pH}=7.5)$ of Urgaha is matched with the highest podoconiosis cases (17) $(23.3 \%)$ of the village similarly; the highest iron concentration $(8.71 \mathrm{mg} / 10 \mathrm{gm})$ in alkaline soil $(\mathrm{pH}=7.4)$ of Osole coincided with higher podoconiosis cases (14) (19.2\%) of the village; conversely, the least iron concentration $(2.93 \mathrm{mg} / 10 \mathrm{gm})$ in acidic soil $(\mathrm{pH}=6.7)$ of Haro was consistent with least podoconiosis cases (5) $(6.8 \%)$ of the village (Table 6).

In the determination of the risk factors associated with podoconiosis, multivariable logistic regression analysis shows that family history (genetics) was a strong risk factor for the disease $(\mathrm{AOR}=16.8,95 \% \mathrm{CI}=8.2-34.5, P \leq 0.001)$. Age (26-40 years), sex (male), and leg hygiene were also strong risk factors (Table 7 ). 
TAвLE 7: Multivariate logistic regression analysis of associated risk factors of podoconiosis cases $(n=73)$ in Jeldu district, West Shoa, Ethiopia.

\begin{tabular}{|c|c|c|c|c|c|}
\hline Factors & & Cases $n(\%)$ & COR (95\% CI) & AOR (95\% CI) & $P$ value \\
\hline \multirow{2}{*}{ Sex } & Male & $48(65.7)$ & $0.45(0.24-86)$ & $2.2(1.16-4.19)$ & 0.02 \\
\hline & Female & $25(34.3)$ & 1 & 1 & 1 \\
\hline \multirow{4}{*}{ Age } & $10-25$ & $12(16.4)$ & $0.72(0.24-2.1)$ & $1.39(0.46-4.18)$ & 0.56 \\
\hline & $26-40$ & $27(37)$ & $0.37(0.15-0.9)$ & $2.7(1.1-6.8)$ & 0.03 \\
\hline & $41-55$ & $21(28.8)$ & $0.60(0.24-1.5)$ & $1.67(0.66-41)$ & 0.28 \\
\hline & $56-70$ & $13(17.8)$ & 1 & 1 & 1 \\
\hline \multirow{3}{*}{ Occupation } & Farmers & $65(89)$ & $0.51(0.17-1.6)$ & $1.95(0.6-6.0)$ & 0.24 \\
\hline & Students & $2(2.7)$ & $1.94(0.26-14)$ & $0.51(0.07-3.9)$ & 0.52 \\
\hline & Others & $6(6.8)$ & 1 & 1 & 1 \\
\hline \multirow{2}{*}{ Family history } & Yes & $51(69.8)$ & $0.06(0.03-0.12)$ & $16.8(8.2-34.5)$ & $\leq 0.001$ \\
\hline & No & $22(30.2)$ & 1 & 1 & 1 \\
\hline \multirow{2}{*}{ Leg hygiene } & Yes & $47(64.4)$ & $3(1.5-60)$ & $0.33(0.17-0-6)$ & 0.002 \\
\hline & No & $26(35.6)$ & 1 & 1 & 1 \\
\hline
\end{tabular}

TABLe 8: Multivariate logistic regression analysis of associated risk factors of LF $(n=32)$ in Jeldu district, West Shoa, Ethiopia.

\begin{tabular}{|c|c|c|c|c|c|}
\hline Factors & & FTS +ve $n(\%)$ & COR $(95 \%$ CI $)$ & AOR $(95 \% \mathrm{CI})$ & $P$ value \\
\hline \multirow{2}{*}{ Sex } & Male & $12(37.5)$ & $1.5(0.68-3.4)$ & $0.66(0.3-1.46)$ & 0.30 \\
\hline & Female & $20(62.5)$ & 1 & 1 & 1 \\
\hline \multirow{4}{*}{ Age } & $10-25$ & 7 (21.9) & $0.92(0.24-3.7)$ & $1.08(0.27-4.3)$ & 0.92 \\
\hline & $26-40$ & $6(18.8)$ & $1.1(0.3-3.7)$ & $0.94(0.27-3.342)$ & 0.90 \\
\hline & $41-55$ & $14(43.8)$ & $0.5(0.17-1.5)$ & $2.00(0.66-6.0)$ & 0.21 \\
\hline & $56-70$ & $5(15.6)$ & 1 & 1 & 1 \\
\hline \multirow{3}{*}{ Occupation } & Farmers & $27(84.4)$ & $0.46(0.058-3.6)$ & $2.2(0.27-17)$ & 0.46 \\
\hline & Students & $4(12.5)$ & $0.27(0.024-2.97)$ & $3.75(0.33-41)$ & 0.28 \\
\hline & Others & $1(3.1)$ & 1 & 1 & 1 \\
\hline \multirow{2}{*}{ Bed net } & Yes & $8(25)$ & $2.5(1.1-6)$ & $0.39(0.16-0.93)$ & 0.03 \\
\hline & No & $24(75)$ & 1 & 1 & 1 \\
\hline \multirow{2}{*}{ Drugs (DEC/IVM) } & Yes & $2(6.3)$ & 1 & 1 & 1 \\
\hline & No & $30(92.7)$ & $1.24 E+10$ & - & - \\
\hline \multirow{2}{*}{ Irrigation } & Yes & $19(59.4)$ & $0.3(0.14-0.67)$ & $3.3(1.49-7.3)$ & 0.003 \\
\hline & No & $13(40.6)$ & 1 & 1 & 1 \\
\hline
\end{tabular}

Among the determining factors identified with regard to LF, odds of LF were high in cases farming besides rivers and/ or performing irrigation work $(\mathrm{AOR}=3.3, \quad 95 \%$ $\mathrm{CI}=1.49-7.3, P=0.003)$. Bed net users also showed statistically significant association with $\operatorname{LF}(P=0.03)$ (Table 8$)$.

\section{Discussion}

Apparently, the present study aimed to investigate the etiology of elephantiasis and associated risk factors of the disease using structured questionnaire, clinical, serological, and parasitological blood examination and soil analysis. In the present study, a screening made by clinical examination following checking of suspected cases using FTS kits identified that the majority of the people developed overt chronic leg(s) swelling with bilaterally asymmetric; the ratio of unilateral to bilateral is $1: 6$. This is consistent with previous study conducted by [17] who reported $1: 8$ from integrated cases of LF and podoconiosis in 20 co-endemic districts of Ethiopia and 1:16 from Midakegn district, Central Ethiopia [18]. The present study identified that none of elephantiasis cases shows any symptom of hydrocele which is the main clinical manifestation of LF. In contrast, [19] had reported 20.7\% hydrocele and $0 \%$ lymphedema in southwestern Ethiopia, Gambella region, whereas $34 \%$ hydrocoele and $8.5 \%$ lymphedema were reported from Kenya [20]. The difference might be due to the difference in the favorability of the environment for mosquito breeding.

Multivariable logistic regression analysis shows that sex has significant statistical association with podoconiosis in agreement with a nationwide study in Ethiopia [21] and a case control study in Northern Ethiopia shows that females were associated with increased risk of podoconiosis [22]. The present study identified that cases of podoconiosis were more in males than in females with male-to-female ratio of 1.9: 1 which was in contrast to [23] in Wayu Tuka district, eastern Wollega, in which male-to-female ratio was $1: 1.58$ and 0.98:1 in Gojjam, Northern Ethiopia [22]. The risk difference could be due to occupationally (agricultural) linked trauma to the feet (poor habit of wearing shoes) and the cumulative effect of long-term exposure to the soil of the area during farming $[24,25]$. Present finding also unfolds that more than half cases of podoconiosis were found in age 
range $26-40$ years similarly; $78 \%$ of cases in Midakegn district, Central Ethiopia, were found in age range 21-60 years [18]. In the present study, of four stages of podoconiosis with characteristics of itchy swelling, shallow skin folds, and mossy lesion were identified by clinical nurses; stage II was the most common, followed by stage I, stage III, and stage IV, respectively. This agreed with nationwide study in Ethiopia $[21,25]$ from Dano district, Central Ethiopia. The present study also shows that stage IV was absent in lower age and appeared at higher age (56-70) accompanied with secondary infection; furthermore, age groups and stages of lymphoedema have significant statistical association and agreed with an idea that incidence and severity of podoconiosis increase with age, likely due to cumulative exposure to irritant soil $[24,26]$.

The current study also suggested that majority of cases of podoconiosis had developed decrease in the size of swelling after wearing covered shoes compared to those who did not wearing shoes; wearing shoes and reduction of swelling have significant statistical association. In line with empirical evidence from Southern Ethiopia, it shows a reduction in leg circumference and an improvement in clinical stage following the use of a simple lymphoedema management method including regular use of footwear, washing of feet with soap, water and an antiseptic, and compression bandage or elevation of legs at night [27]. Multivariable logistic regression analysis also shows that family history and leg hygiene were significantly associated with podoconiosis. In line with [28], odds of podoconiosis were 16.8 times higher on family history with the disease than those who are not. This might be due to the effect of genes in the development of podoconiosis; this result still requires further genetic analysis. The risk of acquiring podoconiosis among participants who washed their leg daily was greatly lower compared to those who washed their leg sometimes. This might be due to the reason that keeping foot hygiene will detach the possible provoking agent away from susceptible hosts and it is consistent with the reports of [29].

In line with $[16,30]$, the present study indicates that highest cases of podoconiosis were identified from village with alkaline soil containing highest concentration of iron, aluminium, and silicon compared to those in village containing lower concentrations of those minerals. Therefore, iron, aluminium, silicon, and probably potassium are the predictors of podoconiosis in Jeldu district.

The present study shows positive cases by FTS kits were higher than those identified by microscope blood smear. The difference might be due to low sensitivity of microscope [31]. This study also indicates that majority of LF cases were females those with high intensity by FTS with female-tomale ratio of $1.7: 1$. The sex difference could be due to high metabolic burdens on females like pregnancy, lactation, and menstruation which probably decrease their immune status [32]. In the current work, multivariable logistic regression analysis for LF indicates that age, bed net, and irrigation farming have strong association with an occurrence of LF which is in agreement with a report from Congo [33].

\section{Conclusions}

The positive cases (30.5\%) identified by both serological and parasitological blood diagnosis indicate the presence of lymphatic filariasis. Also, soil analysis and clinical examination of leg(s) swelling indicate (69.5\%) the presence of podoconiosis in the study area. Based on this evidence, we conclude that both etiologies of elephantiasis, filarial elephantiasis and endemic non-filarial elephantiasis (podoconiosis), are available in Jeldu district. We recommend that integrated interventions and rapid re-assessment of these diseases should be taken into account to avail medications and treatment materials for the community.

\section{Data Availability}

The dataset generated from patients' clinical record is not publicly available to protect patient confidentiality. Unidentifiable data can be obtained from the corresponding author upon reasonable request.

\section{Ethical Approval}

Ethical clearance was obtained from Wollega University Research Ethics Review Committee. In addition, positive cases for any intestinal parasites were treated and confidentiality of data and information from this study was maintained.

\section{Consent}

Written informed consent was obtained from each guardian/parent.

\section{Conflicts of Interest}

The authors declare no conflicts of interest.

\section{Authors' Contributions}

M. D. and A. N. conceptualized the idea and drafted the initial proposal. A. N. finalized the study proposal. M. D. and A. N. led the development of the data collection tools. A. N. contributed to data processing and analysis. M. D. and A. N. drafted the manuscript. Both authors read and approved the manuscript.

\section{Acknowledgments}

Special thanks are due to Jeldu Hospital health workers, clinical nurses, and laboratory technicians for their professional assistance in blood sample collection, clinical diagnosis, and parasitological and serological blood examination. The authors are also grateful to study participants for their participation in the study. They also thank Holeta Agricultural Research Center (HARC) for their soil mineral analysis and Ethiopia Public Health Institute (EPHEI) for FTS kits support. The authors are deeply indebted to Wollega University, Department of Biology, for 
computer support throughout the academic and research progress.

\section{References}

[1] V. Khieu, V. Or, C. Tep et al., "How elimination of lymphatic filariasis as a public health problem in the kingdom of Cambodia was achieved," Infectious Diseases of Poverty, vol. 7, no. 1, p. 15, 2018.

[2] J. O. Gyapong, V. Kumaraswami, G. Biswas, and E. A. Ottesen, "Treatment strategies underpinning the global programme to eliminate lymphatic filariasis," Expert Opinion on Pharmacotherapy, vol. 6, no. 2, pp. 179-200, 2005.

[3] B. Mengitsu, O. Shafi, B. Kebede et al., "Ethiopia and its steps to mobilize resources to achieve 2020 elimination and control goals for neglected tropical diseases: spider webs joined can tie a lion," International Health, vol. 8, no. s1, pp. i34-i52, 2016.

[4] K. Deribe, J. Cano, M. L. Trueba, M. J. Newport, and G. Davey, "Global epidemiology of podoconiosis: a systematic review," PLoS Neglected Tropical Diseases, vol. 12, no. 3, Article ID e0006324, 2018.

[5] E. McConnel and M. L. Schmidt, "Bancrofti an filariasis in gambela, illubabor province, Ethiopia," Tropical and Geographical Medicine, vol. 25, no. 3, pp. 300-303, 1973.

[6] H. Sime, K. M. Gass, S. Mekasha et al., "Results of a confirmatory mapping tool for lymphatic filariasis endemicity classification in areas where transmission was uncertain in Ethiopia," PLoS Neglected Tropical Diseases, vol. 12, no. 3, Article ID e0006325, 2018.

[7] E. Mousley, K. Deribe, A. Tamiru, and G. Davey, "The impact of podoconiosis on quality of life in northern Ethiopia," Health and Quality of Life Outcomes, vol. 11, no. 1, p. 122, 2013.

[8] E. W. Price, Podoconiosis: Non-Filarial Elephantiasis, Oxford University Press, Oxford, UK, 1990.

[9] G. Alemu, F. Tekola Ayele, T. Daniel, C. Ahrens, and G. Davey, "Burden of podoconiosis in poor rural communities in gulliso woreda, west Ethiopia," PLoS Neglected Tropical Diseases, vol. 5, no. 6, Article ID e1184, 2011.

[10] A. P. Oomen, "Studies on elephantiasis of the legs in Ethiopia," Tropical and Geographical Medicine, vol. 21, no. 3, pp. 236-253, 1969.

[11] G. Davey, "Podoconiosis, non-filarial elephantiasis, and lymphology," Lymphology, vol. 43, no. 4, pp. 168-177, 2010.

[12] M. P. Rebollo, S. M. Sambou, B. Thomas et al., "Elimination of lymphatic filariasis in the Gambia," PLoS Neglected Tropical Diseases, vol. 9, no. 3, Article ID e0003642, 2015.

[13] F. Tekola, Z. Ayele, D. H. Mariam, C. Fuller, and G. Davey, "Development and testing of ade novoclinical staging system for podoconiosis (endemic non-filarial elephantiasis)," Tropical Medicine \& International Health, vol. 13, no. 10, pp. 1277-1283, 2008.

[14] G. J. Weil, K. C. Curtis, L. Fakoli et al., "Laboratory and field evaluation of a new rapid test for detecting wuchereria bancrofti antigen in human blood," The American Journal of Tropical Medicine and Hygiene, vol. 89, no. 1, pp. 11-15, 2013.

[15] S. Wanji, M. E. Esum, A. J. Njouendou et al., "Mapping of lymphatic filariasis in loiasis areas: a new strategy shows no evidence for Wuchereria bancrofti endemicity in Cameroon," PLoS Neglected Tropical Diseases, vol. 13, no. 3, Article ID e0007192, 2019.

[16] J. Muli, J. Gachohi, and J. Kagai, "Soil iron and aluminium concentrations and feet hygiene as possible predictors of podoconiosis occurrence in Kenya," PLoS Neglected Tropical Diseases, vol. 11, no. 8, Article ID e0005864, 2017.

[17] B. Kebede, S. Martindale, B. Mengistu et al., "Integrated morbidity mapping of lymphatic filariasis and podoconiosis cases in 20 co-endemic districts of Ethiopia," PLoS Neglected Tropical Diseases, vol. 12, no. 7, Article ID e0006491, 2018.

[18] G. Geshere Oli, F. Tekola Ayele, and B. Petros, "Parasitological, serological and clinical evidence for high prevalence of podoconiosis (non-filarial elephantiasis) in Midakegn district, central Ethiopia," Tropical Medicine \& International Health, vol. 17, no. 6, pp. 722-726, 2012.

[19] L. Jemaneh and D. Kebede, "Clinico-epidemiological study of lymphatic filariasis southwestern Ethiopia," Ethiopian Medical Journal, vol. 33, no. 3, pp. 143-153, 1995.

[20] S. M. Njenga, C. N. Wamae, D. W. Njomo, C. S. Mwandawiro, and D. H. Molyneux, "Chronic clinical manifestations related to wuchereria bancrofti infection in a highly endemic area in Kenya," Transactions of the Royal Society of Tropical Medicine and Hygiene, vol. 101, no. 5, pp. 439-444, 2007.

[21] K. Deribe, S. Wanji, O. Shafi et al., "The feasibility of eliminating podoconiosis," Bulletin of the World Health Organization, vol. 93, no. 10, pp. 712-718, 2015.

[22] Y. B. Molla, S. Tomczyk, T. Amberbir, A. Tamiru, and G. Davey, "Podoconiosis in East and west gojam zones, northern Ethiopia," PLoS Neglected Tropical Diseases, vol. 6, no. 7, Article ID e1744, 2012.

[23] K. Bekele, K. Deribe, T. Amberbir, G. Tadele, G. Davey, and A. Samuel, "Burden assessment of podoconiosis in WayuTukaworeda, east Wollega zone, western Ethiopia: a community-based cross-sectional study," BMJ Open, vol. 6, no. 9, Article ID e012308, 2016.

[24] H. Kloos, A. B. Kello, and A. Addus, "Podoconiosis (endemic non-filarial elephantiasis) in two resettlement schemes in western Ethiopia," Tropical Doctor, vol. 22, no. 3, pp. 109-112, 1992.

[25] F. Dejene, H. Merga, and H. Asefa, "Community based cross sectional study of podoconiosis and associated factors in Dano district, central Ethiopia," PLoS Neglected Tropical Diseases, vol. 13, no. 1, Article ID e0007050, 2019.

[26] D. H. Molyneux, "Tropical lymphedemas-control and prevention," New England Journal of Medicine, vol. 366, no. 13, pp. 1169-1171, 2012.

[27] F. Tekola Ayele, A. Adeyemo, C. Finan et al., "HLA class II locus and susceptibility to podoconiosis," New England Journal of Medicine, vol. 366, no. 13, pp. 1200-1208, 2012.

[28] P. Nenoff, J. C. Simon, G. K. Muylowa, and G. Davey, "Podoconiosis-non-filarial geochemical elephantiasis-a neglected tropical disease?" JDDG: Journal der Deutschen Dermatologischen Gesellschaft, vol. 8, no. 1, pp. 7-14, 2010.

[29] B. E. Feleke, "Determinants Of podoconiosis, a case control study," Ethiopian Journal of Health Sciences, vol. 27, no. 5, pp. 501-506, 2017.

[30] B. Visser, "How soil scientists help combat podoconiosis, a neglected tropical disease," International Journal of Environmental Research and Public Health, vol. 11, no. 5, pp. 5133-5136, 2014.

[31] G. Dreyer, A. Pimentael, Z. Medeiros et al., "Studies on the periodicity and intravascular distribution of Wuchereria bancrofti microfilariae in paired samples of capillary and venous blood from Recife, Brazil," Tropical Medicine \& International Health, vol. 1, no. 2, pp. 264-272, 1996.

[32] I. Malhotra, P. L. Mungai, A. N. Wamachi et al., "Prenatal T cell immunity toWuchereria bancrofti and its effect on filarial immunity and infection susceptibility during 
childhood," The Journal of Infectious Diseases, vol. 193, no. 7, pp. 1005-1013, 2006.

[33] C. B. Chesnais, N. P. Awaca-Uvon, J. Vlaminck et al., "Risk factors for lymphatic filariasis in two villages of the democratic republic of the Congo," Parasites \& Vectors, vol. 12, no. 1, p. 162, 2019. 